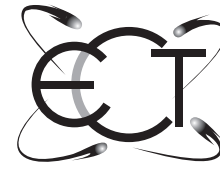

\section{ECT Internship:}

\section{An Unparalleled Opportunity}

\section{By Eunjung Oh}

I remember my first day of freshman orientation at Ewha Womans University in Korea, as one of 60 freshman students newly admitted in the Department of Educational Technology. Dr. Myunghee Kang, department head at that time, led the orientation and introduced us to the ET department and to the field of educational technology. I was overwhelmed with the excitement of becoming a college student as well as engaging with this fascinating new major, Educational Technology, that has been a significant part of my life ever since.

At the 2009 AECT convention in Louisville, Kentucky when I was introduced as an ECT foundation Intern, I experienced that same excitement. I also felt an indescribable gratefulness for what this field has provided to me for the past 13 years. How much I have learned, how much I have grown as a professional, how many wonderful mentors and friends I have met over the past years...

However, that moment of excitement, honor and gratitude was merely the beginning to my ECT Internship experience. That brief week at the convention changed me greatly in that I gained fresh insights as well as a new perspective and identity regarding the field and the organization. After that week, AECT has become more a community to which I want to contribute rather than merely an organization of which I am a member.

The ECT internship program is about nurturing the field's next generation leaders and continuously supporting them in carrying on its



Eunjung Oh

legacy of educational innovations and achievements through leadership in scholarship and service. Interns are given many opportunities to participate in meetings and gatherings and be exposed to the current leaders' contributions. It has truly been an authentic and dynamic experience to learn about the field and its community of scholars, along with an opportunity to consider how I can contribute and serve this group as a younger generation member. I truly sensed the respect and commitment of our leaders toward the field and community, realizing once again that leadership is more than scholarship alone, but also includes spirit of service.

Interns also have another important advantage in the numerous direct and indirect opportunities to be mentored. My two favorites were the breakfast mentoring sessions and the shadowing opportunities. Every morning we had breakfast with one of the leaders in ET, Drs. Hannafin, Jonassen, and Gibbons. They shared valuable advice and insights on many different areas, from their scholarly interests to career development. After many months, the conversations remain quite deeply fixed in my heart, and have provided me with valuable encouragement and motivation. Additionally, Drs. Ana Donaldson and Michael Spector, both active leaders in AECT, generously allowed me to shadow them. For a few hours as I followed them, I was introduced to many people they met, observed how they enacted leadership roles, and participated in enjoyable conversations regarding our scholarly interests.

Finally, I also appreciate the networking and friendship opportunities provided by the internship. Many people welcomed and encouraged me greatly at the convention, and it was wonderful to see some of them during this years' PIDT meeting. I also met four other interns, Nari, Abby, Heather, and Evrim, and we as a group are becoming academic partners, friends, and supporters for each other's professional development. We enjoyed working together on our service project, a panel session we facilitated at the 2010 AECT Convention. It was about empowering women's leadership in educational technology by learning from women who successfully developed their scholarship, careers, and leadership. The panel session was our beginning step of service to the community. We hope our wonderful panelists inspired many graduate students and people in their early careers.

As a final remark, I would like to strongly encourage graduate students to apply for this Internship program. Being an Intern is more than a great honor; it is also a truly transforming experience. If you are selected, without a doubt, it will be one of the best opportunities for you as an Educational Technologist.

EunjungOh (ejgraceoh@gmail.com) is a Ph.D. candidate in Learning, Design, \& Technology at The University of Georgia. 